\title{
A Research on the Dynamic System Model for E-commerce Enterprises' Innovation and Development
}

\author{
Wei Guo-chen ${ }^{1}$, Liu Shuai ${ }^{1}$, Jiang Li $^{2}$ \\ ${ }^{1}$ School of Business, Beijing Wuzi University, Beijing, China \\ ${ }^{2}$ School of Information, Beijing Wuzi University, Beijing, China \\ Email address: \\ 18813053923@163.com (Liu Shuai),694947578@qq.com (Wei Guochen), 1373738151@qq.com (Jiang Li)
}

\section{To cite this article:}

Wei Guo-chen, Liu Shuai, Jiang Li. A Research on the Dynamic System Model for E-commerce Enterprises' Innovation and Development. Science Journal of Business and Management. Vol. 4, No. 4, 2016, pp. 132-136. doi: 10.11648/j.sjbm.20160404.15

Received: July 13, 2016; Accepted: July 25, 2016; Published: August 4, 2016

\begin{abstract}
As the consumption level and the living quality have increased considerably, e-commerce has been an important part of people's lives and the development of e-commerce enterprises are also more noticeable. Innovation is the key to e-commerce enterprises' development. This paper proposes a method which refers to spatial concurrent force system can analyze dynamic system for e-commerce enterprises' innovation and development. Lastly, this paper makes conclusions that the dynamic system for e-commerce enterprises' innovation and development is a resultant force which is synthesized by each component force.
\end{abstract}

Keywords: E-commerce Enterprises, Innovation and Development, Dynamic System, Spatial Concurrent Force System

\section{Introduction}

Aiming at the problem of e-commerce enterprises' innovation and development, many scholars from different aspects make the different studies. Generally speaking, it can be summarized as the following two aspects. On the one hand, some scholars researched on model innovation of e-commerce enterprises. For instance, Shao Ming (2013) presented a model which integrated QFD and TRIZ for business model innovation. This model can avoid the randomness and blindness in process of the design of business mode's innovation [1]. On the other hand, some scholars research for innovation in all aspects of e-commerce enterprises operational processes. For instance, Wei Guochen (2015) proposed a new model of $3 \mathrm{PL}$ and consumers carrying or third party distribution for the fresh products e-commerce enterprises logistics issues. This model can help the enterprises to concentrate on their core business and reduce logistic cost [2]. Zhang Yaming et al (2014) analyzed the marketing strategy of e-commerce enterprises case. Then he proposed five kinds of marketing innovation, namely reverse marketing, network marketing, online word of mouth marketing, the demand for game marketing and transfer pricing strategy marketing [3].
In conclusion, although many scholars made difficult researches about e-commerce enterprises' innovation and development, scholars researched on the dynamic system for e-commerce enterprises' innovation and development are little. Firstly, this paper establishes a model of dynamic system for e-commerce enterprises' innovation and development. Then authors analyze the operation mechanism of this model. Finally, authors use spatial concurrent force system to research this model. The authors obtain conclusions that the dynamic system of e-commerce enterprises' innovation and development is the resultant effect of various factors together and can be researched further by force analysis.

\section{The Establishment of Dynamic System Model}

This paper establishes dynamic system models for e-commerce enterprises' innovation and development, which includes the automatic force subsystem, the environment force subsystem and the cultural force subsystem. Among them, the automatic force subsystem includes four aspects: economic interests target and its driven force, subjective innovation value and its influential force, innovation incentive mechanism and its catalytic force, necessary for Long-term 
development and its durable force. The environment force subsystem includes four aspects: market demand and its pulling force, market competition and its stress force, market resources and its constrained force, governmental measures and its guiding force. The cultural force subsystem includes two aspects: corporate culture and its appeal force, social culture and its pushing force.

The factors of dynamic system models are interactional and interdependent. These factors are mutually inhibited when their forces have opposite direction. And when their forces have same direction, these factors are mutually reinforcing relationship. Besides, the different subsystems also affect each other. Therefore, the open circumferential dynamic model of e-commerce enterprises' innovation and development is just as Figure 1 shown.

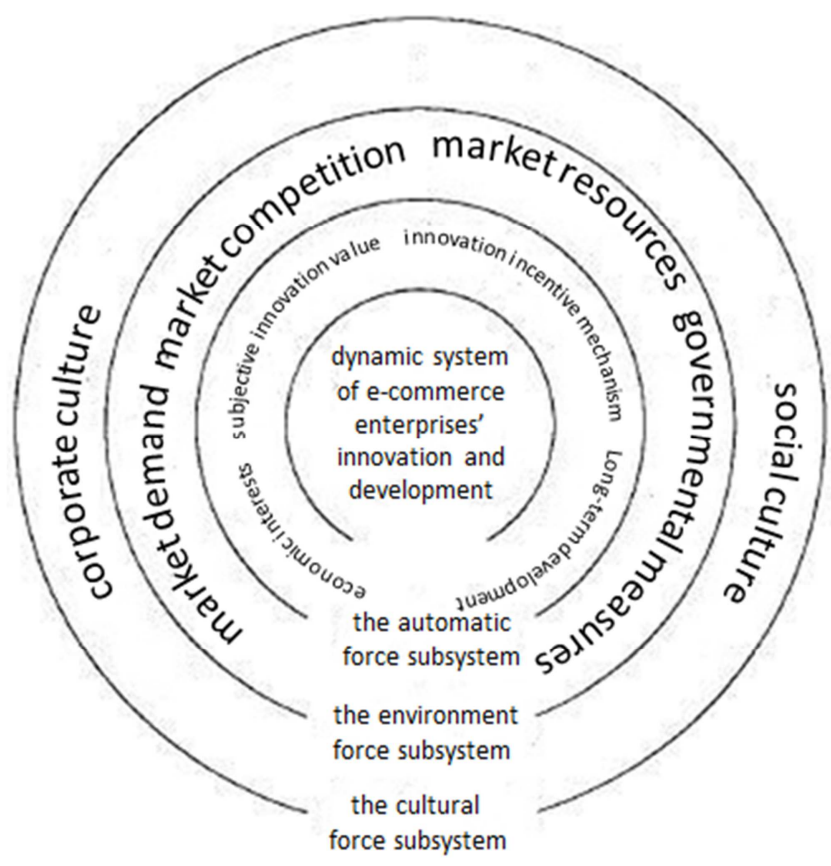

Figure 1. Open circumferential dynamic model.

\section{Analysis of Operation Mechanism of Dynamic System}

\subsection{The Dynamic Factors and the Roles of the Dynamic System}

\subsubsection{The Automatic Force Subsystem}

1) Economic interest target is the pursuit of excess profits in the e-commerce enterprises. The survival motivation of e-commerce enterprises is the driving force of economic benefits maximization. In order to achieve the goal of maximizing economic benefits, the enterprises can take the innovation and development as the core competence [4]. The function of economic interest target is driving the e-commerce enterprises innovation and development.

2) The value of subjective innovation refers to the innovation consciousness, innovation demand and leaders' sense of crisis. We need to be clear that the leaders are the core strength of enterprises' innovation and development. If the leaders hold a strong sense of innovation, they can lead the whole enterprise to innovate and change.

3) Innovation incentive mechanism is a number of measures which can encourage various forms of innovation form policy makers, technical staff, managers and ordinary employees [5]. The reasonable innovation incentive mechanism can stimulate the innovation enthusiasm and the desire of the related personnel. The function of this factor is producing and reinforcing the e-commerce enterprises innovation and development.

4) The need for long term development can realize the enduring and healthy development of enterprises. It makes the enterprises be in a dominant position among market competition. In an increasingly competitive environment, long-term development is the lasting goal of the enterprise. This factor is able to maintain the sustainable development of innovation and development of e-commerce enterprises.

\subsubsection{The Environment Force Subsystem}

1) Market demand is the basic starting point for the innovation and development of business enterprises, including consumer demand for products, services and demand for the development of business enterprises. Meeting the market demand not only provide e-commerce enterprises with the opportunity to get a profit, but also bring the market competition [6]. E-commerce enterprises obtain competitive advantage through innovation and development, and it will better satisfy the market demand, get more profit and promote well cycle development. The function of this factor is pulling and stimulating the e-commerce enterprises' innovation and development.

2) Market competition is the response measures taken by e-commerce enterprises in the face of peer competition. If companies want to ensure that they are not eliminated in the competition, it is necessary to enhance their competitive strength by various means. Market competition is the pressure on the innovation and development of the business enterprise.

3) Market resource includes human resources, material resources, information resources, assets and natural resources in the process of e-commerce enterprises' innovation and development. If some conditions are not satisfied, it will inevitably lead to the bottleneck and restriction of e-commerce enterprises.

4) Government measures are the policy and legal system that the government needs to make to develop the innovation and development of enterprises in different levels of society according to the needs of national economic development. E-commerce enterprises can be based on government measures to develop and innovate in a directive and purposive way. Government 
measures are regarded to be the guiding force for the development and innovation of e-commerce enterprises [6].

\subsubsection{The Cultural Force Subsystem}

1) Enterprise culture is the sum of the value idea, the team consciousness, the behavior way and the thought pattern of the enterprise. Enterprise culture exerts a subtle influence on the enterprise's decision-making, operation and innovation. The corporate culture of encouraging innovation and tolerating failure plays an important role in the innovation and development of e-commerce enterprises. Enterprise culture is an infectious force in the process of innovation and development of e-commerce enterprises.

2) The social culture is the influence of the innovation culture on the enterprises innovation development in the macro social environment of the enterprises. Encouraging innovative social culture can promote the development of e-commerce enterprises, so e-commerce enterprise does not fear failure in the face of innovation risk. The role of social culture is to promote innovation and development of e-commerce enterprises.

\subsection{Analysis of Interaction Among the Dynamical Systems}

\subsubsection{Analysis of Interaction Among Factors in the Automatic Force Subsystem}

Economic interest target can generate the driving force for e-commerce enterprises' innovation and development. It will make e-commerce enterprises improve labor productivity to obtain excess profits and achieve long-term development. Subjective innovation value will exert a subtle influence on economic benefits and long-term development of e-commerce enterprises [7]. The subjective innovation value of encouraging innovation can make enterprises overcome difficulties, improve profit and realize long-term development. Innovation incentive mechanisms have a direct catalytic effect for innovation and development. The reasonable degree of innovation incentive mechanisms has a close interaction with the realization of economic benefits, the formation of subjective innovation value and the long-term development of enterprises.

\subsubsection{Analysis of Interaction Among Factors in the Environment Force Subsystem}

Lower market demands and shortage of resources will lead to increase market competition among e-commerce enterprises. huge competitive pressure will promote e-commerce enterprises putting more focus on scientific research and innovation. Only in this way can e-commerce enterprises enhance their core competitiveness and realize their innovation and development [8]. The government's policy just likes one pair of visible hands which can carry out macroeconomic regulation on market demand, market resources and competition. And it will guide the innovation and development of e-commerce enterprises actively.

\subsubsection{Analysis of Interaction Among Factors in the Cultural Force Subsystem}

The culture of enterprises is the sum total of some stable cultural concept, code of conduct and standard of morality which are formed in the development of enterprises and united in the same direction of enterprises. The culture of e-commerce enterprises has a strong influence on the value pursuit, innovation direction and the way of realization.

Enterprises' culture will be influenced by social culture. If social culture is inspiring and tolerant, e-commerce enterprises will establish their culture that enterprises encourage employees to innovate and inclusive their failures [9]. On the contrary, when most of enterprises are constantly innovating, they will form a trend of social and cultural innovation.

\subsubsection{Analysis of Interaction Among Subsystems}

The relationship among three subsystems of dynamical systems is mutual influence. The market conditions and policies factors of environmental subsystem directly affect the economic benefits, subjective innovation value, innovation incentive mechanism and long-term development of automatic force system [10]. On the other hand, the changes in the system of automatic force subsystem can promote the formation of the environmental subsystem. Culture subsystem and environment subsystem are interaction effect. The changes of social culture and enterprise culture are affected by the factors of environment subsystem. Social culture and enterprise culture of culture subsystem is the value orientation of automatic force subsystem. On the contrary, the adjustment of automatic force subsystem will have indirect influence on social culture and enterprise culture [11].

In summary, interaction among dynamical systems as shown in figure 2 :

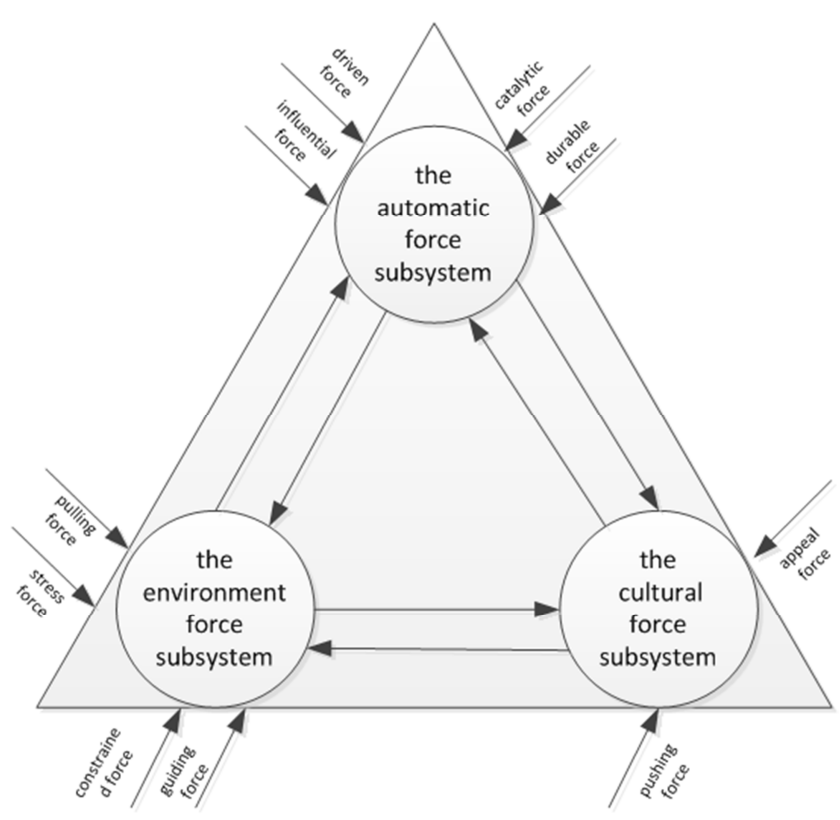

Figure 2. Interaction among dynamical systems. 


\section{Analysis Based on the Spatial Concurrent Force System}

The spatial concurrent force system is theoretical mechanical concept, which means that the line of each force is summarized in one point in space force systems. This chapter uses the method which for calculating the resultant force of the spatial concurrent force system, to research the force effect of dynamic system.

\subsection{Projection and Decomposition of Any Force in Space Rectangular Coordinate Axes}

1) Calculation of the force size in the coordinate axis

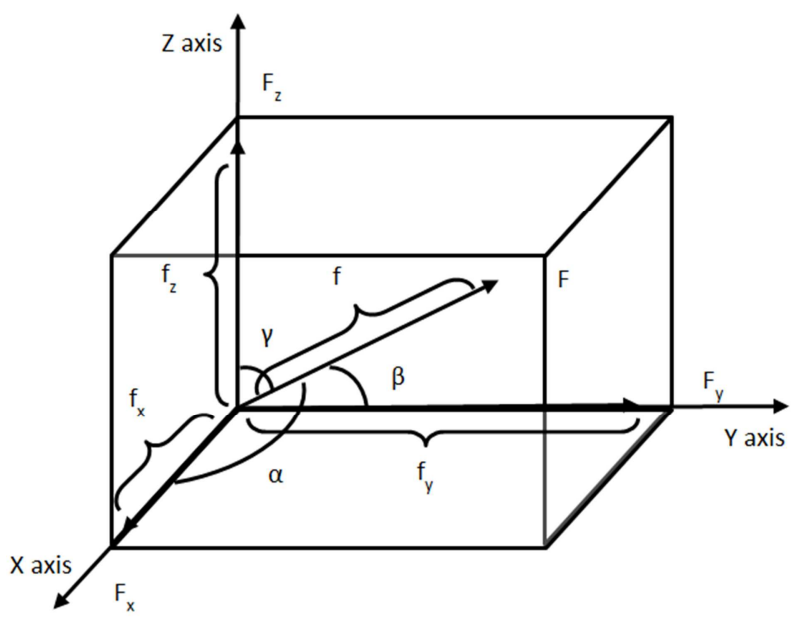

Figure 3. The projection and decomposition of force $f$ in the dynamic system for e-commerce enterprises'innovation.

Assuming one force vector which belongs to dynamic system for e-commerce enterprises' innovation and development is $\mathrm{F}$, as shown in figure 3 . Assuming the force size is $\mathrm{f}$. $\mathrm{F}$ and space coordinates in the $\mathrm{X}$ axis, $\mathrm{Y}$ axis, $\mathrm{Z}$ axis of the included angle are $\alpha, \beta, \gamma$. According to the decomposition rule of space force system, this paper calculates $\mathrm{F}$ decomposition to the three components on the shaft by direct projection method. If the projection direction is in the same direction as the three axes, the projection is positive, or else negative. These force sizes are fx, fy, fz:

$$
f x=f \cdot \cos \alpha, f y=f \cdot \cos \beta ; f z=f \cdot \cos \gamma
$$

2) Decomposition of any force along the direction of the coordinate axes.

The authors make the arbitrary force $\mathrm{F}$ decompose along the axis of the coordinate and get three component forces Fx, Fy, $\mathrm{Fz}$. So the force $\mathrm{F}$ is:

$$
\mathrm{F}=\mathrm{Fx}+\mathrm{Fy}+\mathrm{Fz}
$$

Combined with formula (1), we can get the force $\mathrm{F}$ of the magnitude and direction of the cosine respectively:

$$
\begin{gathered}
f=\sqrt{\left(f x^{2}+f y^{2}+f z^{2}\right)} \\
\cos \alpha=f x / f, \cos \beta=f y / f, \cos \gamma=f z / f
\end{gathered}
$$

\subsection{Example Application of the Spatial Concurrent Force System}

In the dynamic system of e-commerce enterprises' innovation and development, respectively, authors use $F_{1}, F_{2}$, $\mathrm{F}_{3}, \mathrm{~F}_{4}$ express 4 force vector of the automatic force subsystem, namely economic interests target and its driven force, subjective innovation value and its influential force, innovation incentive mechanism and its catalytic force, necessary for long-term development and its durable force. Then, authors use $\mathrm{F}_{5}, \mathrm{~F}_{6}, \mathrm{~F}_{7}, \mathrm{~F}_{8}$ express 4 force vector of the environment force subsystem, namely market demand and its pulling force, market competition and its stress force, market resources and its constrained force, governmental measures and its guiding force. Lastly, authors use $F_{9}, F_{10}$ express 2 force vector of the cultural force subsystem, namely corporate culture and its appeal force, social culture and its push force.

Assuming the resultant force vector of the dynamical system is $M$, namely the resultant force of the spatial concurrent force system. The numerical value of $\mathrm{M}$ is $\mathrm{m}$, and it with the angle between the $\mathrm{X}$ axis, $\mathrm{Y}$ axis, $\mathrm{Z}$ axis is $\chi, \psi, \omega$.

According to the combination rule of space concurrent force: resultant force is equal to the vector sum and its action line of force is through the intersection Therefore, the resultant force $\mathrm{M}$ is:

$$
M=F_{1}+F_{2} \ldots \ldots+F_{9}+F_{10}=\sum_{i=1}^{10} F_{i}
$$

The force polygon space is formed by the dynamic system of spatial concurrent force system. Assuming the resultant force $\mathrm{M}$ in $\mathrm{X}$ axis, $\mathrm{Y}$ axis, $\mathrm{Z}$ axis projection component size are $\mathrm{m}_{\mathrm{x}}, \mathrm{m}_{\mathrm{y}}, \mathrm{m}_{\mathrm{z}}$, so:

$$
\mathrm{m}_{\mathrm{X}}=\sum_{\mathrm{i}=1}^{10} \mathrm{f}_{\mathrm{x}_{\mathrm{i}}} \quad \mathrm{m}_{\mathrm{Y}}=\sum_{\mathrm{i}=1}^{10} \mathrm{f}_{\mathrm{y}_{\mathrm{i}}} \quad \mathrm{m}_{\mathrm{Z}}=\sum_{\mathrm{i}=1}^{10} \mathrm{f}_{\mathrm{z}_{\mathrm{i}}}
$$

With the same method of formula (3) and formula (4), we can calculate the size and the cosine of direction of the resultant $\mathrm{M}$ :

$$
\begin{gathered}
\mathrm{m}=\sqrt{\left(\mathrm{m}_{\mathrm{x}}{ }^{2}+\mathrm{m}_{\mathrm{y}}{ }^{2}+\mathrm{m}_{\mathrm{z}}{ }^{2}\right)} \\
\cos \chi=\mathrm{m}_{\mathrm{x}} / \mathrm{m}, \cos \psi=\mathrm{m}_{\mathrm{y}} / \mathrm{m}, \cos \omega=\mathrm{m}_{\mathrm{z}} / \mathrm{m}
\end{gathered}
$$

\section{Conclusions}

From the perspective of system, this paper carries out researching the force of e-commerce enterprises' innovation and development. Then this paper makes dynamic system divided into three segments, namely the automatic force subsystem, the environment force subsystem, the cultural force subsystem. And authors analyze the structure, function and operation mechanism of this dynamic system in depth profoundly. Next, it is by the theory of the Spatial Concurrent Force System that authors analyze dynamic system for e-commerce enterprises' innovation and development. Ultimately, authors make conclusions that the interaction of different force forms this dynamic system and every force can be calculated with using method for synthesizing the spatial 
concurrent force system. All the researches which have done in this paper are meant to provide method to analyze dynamic system of e-commerce enterprises' innovation and development.

\section{Acknowledgements}

This paper is supported by the Funding Project for Research on the innovation and development of Tongzhou District trade and Industry under the International Trade Center (ID: PXM2014-014214-000073). The authors would like to deeply thank this project for the generous support.

\section{References}

[1] Shao Ming. Research on Business Model Innovation of the E-commerce Enterprises Integrated with QFD and TRIZ [D]. Yangzhou University, 2013.

[2] Wei Guochen. Study on the Innovation of Fresh Products Logistics Model In Chinese E-commerce Enterprises [J]. China Business and Market, 2015. 5 (43-50).

[3] Zhang Yaming, Zhang Bosong, Zhang Xiyu. Marketing Strategy Innovation of E-commerce Enterprise Market Development $[\mathrm{J}]$. China Journal of Commerce, 2014. 25 (29-30).

[4] Adel. A. Alyoubi. E-commerce in Developing Countries and
How to Develop Them During [J]. Procedia Computer Science, 2015. 10 (479-483).

[5] Ghobakhloo Morteza, Tang Sai Hong, Standing Craig. B2B E-Commerce Success among Small and Medium-Sized Enterprises: A Business Network Perspective [J]. Journal of Organizational \& End User Computing, 2013. 27 (23-32).

[6] Minna Halme, Maria Korpela. Responsible Innovation Toward Sustainable Development in Small and Medium-Sized Enterprises: a Resource Perspective [J]. Business Strategy and the Environment, 2014. 8 (547-566).

[7] Youcef Baghdadi. A framework for social commerce design [J]. Information Systems, 2016. 8 (95-113).

[8] Grochal magdalena. Methodology of Research on Internationalisation Process of E-Commerce Enterprises [J]. Management, 2016. 16 (51-66).

[9] Sungmin Park, Analyzing the efficiency of small and medium-sized enterprises of a national technology innovation research and development program [J]. Springer Plus, 2014. 3 (403).

[10] Duplenko, Natalia. The development of a mechanism for stimulating the innovative activity of small enterprises [J]. Vestnik Immanuel Kant Baltic Federal University, 2013. 3 (107-113).

[11] Mokter Hossain. A review of literature on open innovation in small and medium-sized enterprises [J]. Journal of Global Entrepreneurship Research, 2015. 1(34-50). 